\title{
Investigation of the Interaction, Rheological and Tribological Properties of Bis(pinacolato)diboron with Lithium Grease
}

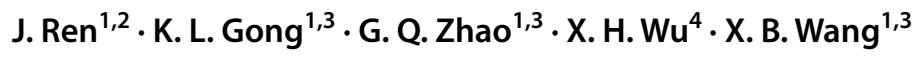

Received: 29 April 2021 / Accepted: 27 September 2021 / Published online: 13 November 2021

(c) The Author(s) 2021

\begin{abstract}
In this article, Lewis acid-base complex of lithium 12-hydroxystearate (LHS) with diboron compound is formed by the introduction of bis(pinacolato)diboron $\left(\mathrm{B}_{2} \mathrm{Pin}_{2}\right)$ into lithium grease. The interaction between Lewis acid $\mathrm{B}_{2} \mathrm{Pin}_{2}$ and Lewis base $\mathrm{RCO}_{2}{ }^{-}$of LHS is characterized by various techniques. Moreover, the rheological and tribological behaviors of the base grease are evaluated at low and moderate temperature. The results indicate that the addition of $\mathrm{B}_{2} \mathrm{Pin}_{2}$ can noticeably enhance the rheological property of the base grease because the formation of Lewis acid-base complex is beneficial for improving the soap fiber structure strength, and $\mathrm{B}_{2} \mathrm{Pin}_{2}$ could also help reduce the friction and wear of the grease during the sliding process, which likely owing to the boundary lubrication film generated by $\mathrm{B}_{2} \mathrm{Pin}_{2}$ adsorption on the rubbing surface and tribochemical reaction between borate esters and steel surfaces. The improvement of mechanical stability and tribological properties is beneficial to increasing the grease service life.
\end{abstract}

\section{Graphical Abstract}

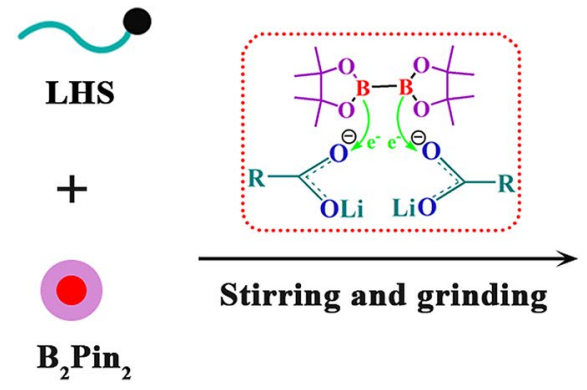

LHS: lithium 12-hydroxystearate B $_{2}$ Pin $_{2}:$ bis(pinacolato)diboron

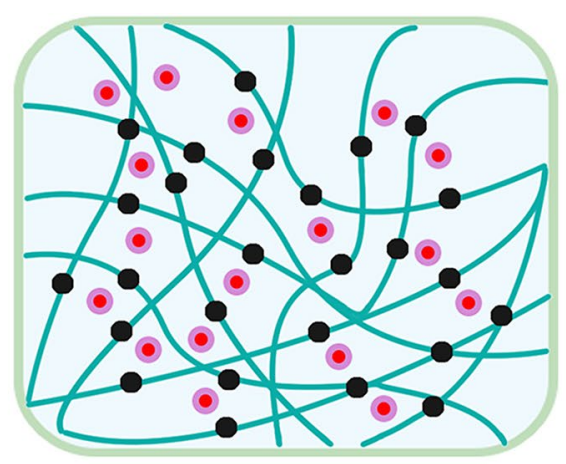

Biboron functionalized fiber structure

Keywords Lithium grease $\cdot$ Diboron compound $\cdot$ Rheological $\cdot$ Friction and wear

X. H. Wu

xinhu.wu@bristol.ac.uk

$\triangle$ X. B. Wang

wangxb@licp.cas.cn

1 State Key Laboratory of Solid Lubrication, Lanzhou Institute of Chemical Physics, Chinese Academy of Sciences, Lanzhou 730000, People's Republic of China
2 University of Chinese Academy of Sciences, Beijing 100049, People's Republic of China

3 Qingdao Center of Resource Chemistry and New Materials, Qingdao 266000, China

4 School of Chemistry, University of Bristol, Cantock's Close, Bristol BS8 1TS, UK 


\section{Introduction}

Bearings are crucial tribological components of many types of machinery. From a small supermarket shopping trolley to huge power plants, a great number of light-duty as well as industrial equipment could not function without the use of bearings in some form. According to a recent study, at least $80 \%$ of bearing failures are related to lubrication $[1,2]$. Therefore, lubrication plays a critical role in the life and performance of bearings in various applications. Grease is the most widely used lubricating material for bearings [3]. To date, up to $90 \%$ of bearings are lubricated with lubricating grease $[4,5]$. Grease mainly consists of a base oil, a thickening agent, and multi-functional lubricant additives, with complex microstructure and physical and chemical properties [6]. In addition to the influences of chemical structure of base oil and additives on the lubricating performance of grease, the micro/nano structural of thickener fiber also has a significant influence on the tribological behaviors and mechanical stability of grease, both determine the grease service life, especially at low temperature and low speeds [7-9].

However, there is room to improve the mechanical stability (rheological parameters) and tribological properties of lubricating grease simultaneously, as increasing the rheological properties of grease usually do not prevent friction and wear reduction. For instance, the lubricating grease based on nano-montmorillonite and castor oil with higher thickener agent (commercial organo-montmorillonite Cloisite 20A) achieved higher friction coefficient at different normal loads (10 N and $30 \mathrm{~N}$ ) [10]. Similar behavior was observed for oleogel-like dispersions containing ethylene vinyl acetate copolymer (EVA) and higholeic sunflower (HOSO) vegetable oil [11]. The reason is that oleogels with lower viscosity and viscoelastic moduli are easier to generate a protective lubricating film in comparison with oleogels with higher viscosity and viscoelastic moduli [10]. Thanks to the good friction reduction and anti-wear (AW) properties, oxidation inhibition, and low toxicity, intensive research has been done on using borates as high-performance and eco-friendly lubricant additives [12-14], and their results indicated that the good tribological performance of borate is ascribe to the boundary lubrication film formed by borate esters adsorbed on the sliding surfaces and tribochemical reaction between borate esters and steel surfaces [14]. In recent years, $\mathrm{Xu}$ et al. has investigated the Lewis acid-base interaction of tributyl borate (TBB) with lithium 12-hydroxystearate (LHS) and indicated that $B$ atoms of TBB can serve as second-level linking points to enhance the structure strength of soap fiber and the colloidal stability of lubricating grease [15]. Moreover, the addition of TBB could improve the tribological performance of lithium grease at elevated temperature. Compared with TBB, diboron compound could contribute to more complex fiber structure by binding each boron atom to one carbonyl oxygen atom of $\mathrm{RCO}_{2}^{-}$in LHS, resulting in marked improvement of the structure strength of lithium grease.

Organic diboron species have been used to modified semiconductor oxide materials due to their unique Lewis acid character and reducing ability [16-18]. Facilitated by the Lewis acid-base interaction between $B$ center of the diboron reagent and the surface bridging $\mathrm{O}_{2 \mathrm{c}}$ of semiconductor oxidematerials (e.g., $\mathrm{TiO}_{2}, \mathrm{ZnO}, \mathrm{SnO}_{2}$ ) nanoparticles, the adsorption of diboron species onto these nanoparticles results in spontaneous electron transfer, leading to various important transformations [16, 17]. This strategy offers an effective approach for functionalizing the fiber structure of lubricating grease. Herein, bis(pinacolato)diboron $\left(\mathrm{B}_{2} \mathrm{Pin}_{2}\right)$ was added into lithiumbased grease to react with the carbonyl oxygen atom of $\mathrm{RCO}_{2}{ }^{-}$in LHS. The Lewis acid-base complex was characterized by several techniques, such as Fourier-transform infrared spectroscopy (FTIR), X-ray photoelectron spectroscopy (XPS), and Transmission Electron Microscopy (TEM). Furthermore, the rheological behavior and tribological property of the lubricating grease with different contents of $\mathrm{B}_{2} \mathrm{Pin}_{2}$ were evaluated at temperatures below $70{ }^{\circ} \mathrm{C}$.

\section{Experimental Section}

\subsection{Materials}

The lithium-based grease was prepared via the same method reported by $\mathrm{Xu}$ et al. [15, 19] and the weight percent of lithium soap was about $12 \mathrm{wt} \%$. Then bis(pinacolato)diboron ( $\mathrm{B}_{2} \mathrm{Pin}_{2}$, purity $\geq 98 \%$, J\&K Scientific Ltd., Beijing, China) was introduced into the base grease. After vigorous mechanical mixing, each sample was ground five times through a
Table 1 Typical properties of lithium-based grease with varying content of $\mathrm{B}_{2} \mathrm{Pin}_{2}$

\begin{tabular}{lcccccc}
\hline Properties & $0 \mathrm{wt} \%$ & $1 \mathrm{wt} \%$ & $3 \mathrm{wt} \%$ & $5 \mathrm{wt} \%$ & $8 \mathrm{wt} \%$ & Test method \\
\hline Cone penetration & 249.5 & 247.1 & 247.4 & 248.2 & 248.8 & ASTM D217 \\
Oil separation (\%) & 1.75 & 1.04 & 0.88 & 0.63 & 0.84 & ASTM D6184 \\
Roll stability & 17.01 & 14.93 & 15.62 & 16.13 & 16.93 & ASTM D1831 \\
\hline
\end{tabular}


Scheme 1 Schematic illustration of the Lewis acid-base interaction of $\mathrm{B}_{2} \mathrm{Pin}_{2}$ with LHS and the influence of $\mathrm{B}_{2} \mathrm{pin}_{2}$ on soap fiber structure of lithium grease

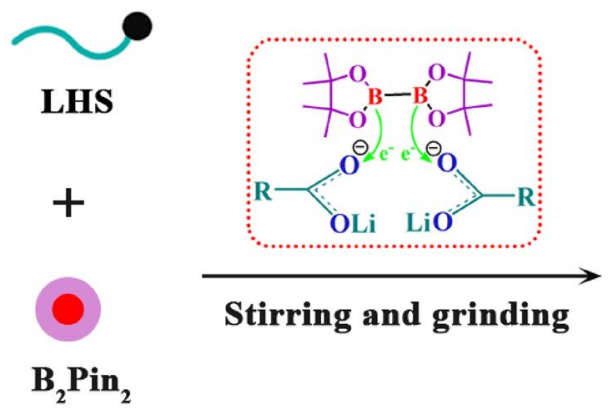

LHS: lithium 12-hydroxystearate
B $_{2}$ Pin $_{2}$ : bis(pinacolato)diboron

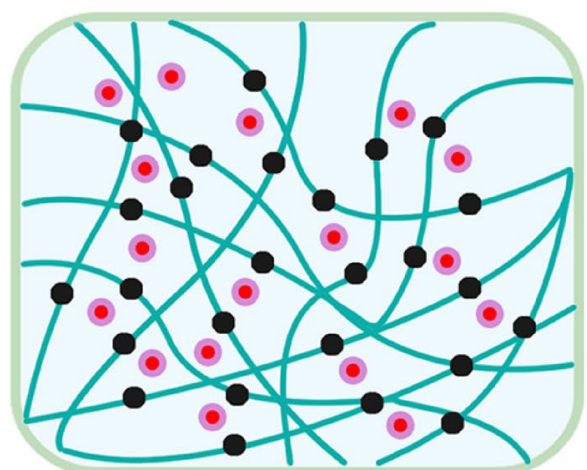

Biboron functionalized fiber structure three-roll mill. Typical properties of the tested grease with various contents of $\mathrm{B}_{2} \mathrm{Pin}_{2}$ are summarized in Table 1 .

Thickener fibers in the greases could be obtained by the following method: $10 \mathrm{~g}$ grease was thoroughly washed with petroleum ether $(3 \times 20 \mathrm{~mL})$ to remove the poly-alpha-olefin (PAO 10) base oil and washed several times with dichloromethane to remove the unreacted biboron. Then the resulting soap fibers (LHS $+\mathrm{B}_{2} \mathrm{Pin}_{2}$ ) were dried under vacuum at $50{ }^{\circ} \mathrm{C}$ overnight.

\subsection{Sample Characterization}

FTIR of the thickener fiber was performed with an IFS 66v/S using the $\mathrm{KBr}$ disk method. TEM images were taken on a JEOL JEM-F200 microscope in TEM mode as well as in annular dark-field (ADF) mode form, operated at $200 \mathrm{kV}$. XPS of the soap fiber was conducted on a Thermo Scientific K-Alpha spectrometer equipped with a monochromatic Al $\mathrm{K} \alpha \mathrm{X}$-ray source $(1486.6 \mathrm{eV})$ operating at $100 \mathrm{~W}$.

Rheological measurements of the tested grease were conducted on an Anton Paar MCR 302 rheometer (Austria) using $1 \mathrm{~mm}$ gap for a plate-to-plate geometry $(24.985 \mathrm{~mm}$ diameter). Oscillatory shear experiments were carried out at a fixed angular frequency $(\omega=10 \mathrm{rad} / \mathrm{s})$ and various shear strains (ranging from 0.01 to $100 \%)$ and temperatures $(0,30$ and $60{ }^{\circ} \mathrm{C}$ ) to evaluate the structure strength of thickener fiber during mechanical aging. Shear measurements were performed at different temperatures $\left(0,30\right.$ and $\left.60{ }^{\circ} \mathrm{C}\right)$ and shear rates $\left(0.01\right.$ and $\left.100 \mathrm{~s}^{-1}\right)$ to reveal the evolution of viscosity as a function of time for the lubricating greases.

To investigate the tribological performances of $\mathrm{B}_{2} \mathrm{Pin}_{2}$ as additives for the lithium-based grease, high contact stress ball-on-disc oscillating reciprocating tribological tests were carried out with an Optimal-SRV-IV tribometer. The AISI 52100 steel balls ( $\phi 10 \mathrm{~mm}$ with hardness of about 626 HV) reciprocated against stationary AISI 52100 steel discs $(\phi 24.00 \times 7.88 \mathrm{~mm}$, hardness $700 \mathrm{HV})$ at a stroke of $1 \mathrm{~mm}$ and an oscillation frequency of $25 \mathrm{~Hz}$. The friction coefficient was collected automatically by a computer connected to the SRV tribometer. Wear volumes of the steel disc were measured with a MicroXAM 3D surface profilometer after each tribological test. The surface composition of the wear disc was obtained with XPS. Note that all experiments were repeated at least three times.

\section{Results and Discussion}

\subsection{Spectroscopic Characterization}

The proposed Lewis acid-base interaction of $\mathrm{B}_{2} \mathrm{Pin}_{2}$ with LHS was shown in Scheme 1. Infrared band assignments of the thickener fibers are reasonable to confirm the formation of Lewis acid base complex (as shown by the red dashed box in Scheme 1). Figure 1a displays the IR spectra between 800 and $2000 \mathrm{~cm}^{-1}$ of various soap fibers (LHS, LHS +1 , 3,5 , and $8 \mathrm{wt} \% \mathrm{~B}_{2} \mathrm{Pin}_{2}$ ) isolated from the base grease containing different concentration of $\mathrm{B}_{2} \mathrm{Pin}_{2}$. Two strong peaks located at $1580 \mathrm{~cm}^{-1}$ and $1559 \mathrm{~cm}^{-1}$ in the spectrum of neat thickener fibers are assigned to $\mathrm{CO}_{2}{ }^{-}$stretching bonds of LHS. When the concentration of $\mathrm{B}_{2} \mathrm{Pin}_{2}$ is $1 \mathrm{wt} \%$, the IR spectrum of LHS $+1 \mathrm{wt} \% \mathrm{~B}_{2} \mathrm{Pin}_{2}$ is similar with that of neat LHS, particularly no obvious $\mathrm{CO}_{2}^{-}$stretching bonds change is observed. When the concentration of $\mathrm{B}_{2} \mathrm{Pin}_{2}$ reaches over $5 \mathrm{wt} \%$, a new broad peak is clearly seen to be centered at around $1636 \mathrm{~cm}^{-1}$, which may be due to the formation of Lewis acid-base complex between boron atom in $\mathrm{B}_{2} \mathrm{Pin}_{2}$ and $\mathrm{CO}_{2}{ }^{-}$of LHS. In this reaction, the boron atom tends to donate an electron pair to the carbonyl oxygen atom resulting in electron-rich $\mathrm{CO}_{2}^{-}$group, so the $\mathrm{CO}_{2}^{-}$stretching band is broadened and shifts to higher frequency with increasing $\mathrm{B}_{2} \mathrm{Pin}_{2}$ concentration. TEM characterization was performed to explore the influence of $\mathrm{B}_{2} \mathrm{pin}_{2}$ on the fibrous microstructure of lithium-based lubricating grease. Although the fiber structures of LHS and LHS $+5 \mathrm{wt} \% \mathrm{~B}_{2} \mathrm{Pin}_{2}$ are similar to each other (Fig. 1b, the TEM image of the fiber morphology of LHS is not shown), the corresponding $\mathrm{C}, \mathrm{O}$, and $\mathrm{B}$ elemental mapping of LHS $+5 \mathrm{wt} \% \mathrm{~B}_{2} \mathrm{Pin}_{2}$ (Fig. 1c-e) 
Fig. 1 a FTIR spectra of LHS and LHS with different concentration of $\mathrm{B}_{2} \mathrm{Pin}_{2}$. b TEM image of the fiber morphology of LHS $+5 \mathrm{wt} \% \mathrm{~B}_{2} \mathrm{Pin}_{2}$ and the corresponding $\mathbf{c} \mathrm{C}, \mathbf{d} \mathrm{O}$, and $\mathbf{e}$ $\mathrm{B}$ elemental mapping. f B 1 s high-resolution XPS spectra for $\mathrm{B}_{2} \mathrm{Pin}_{2}$ and $\mathrm{LHS}+5 \mathrm{wt} \% \mathrm{~B}_{2} \mathrm{Pin}_{2}$
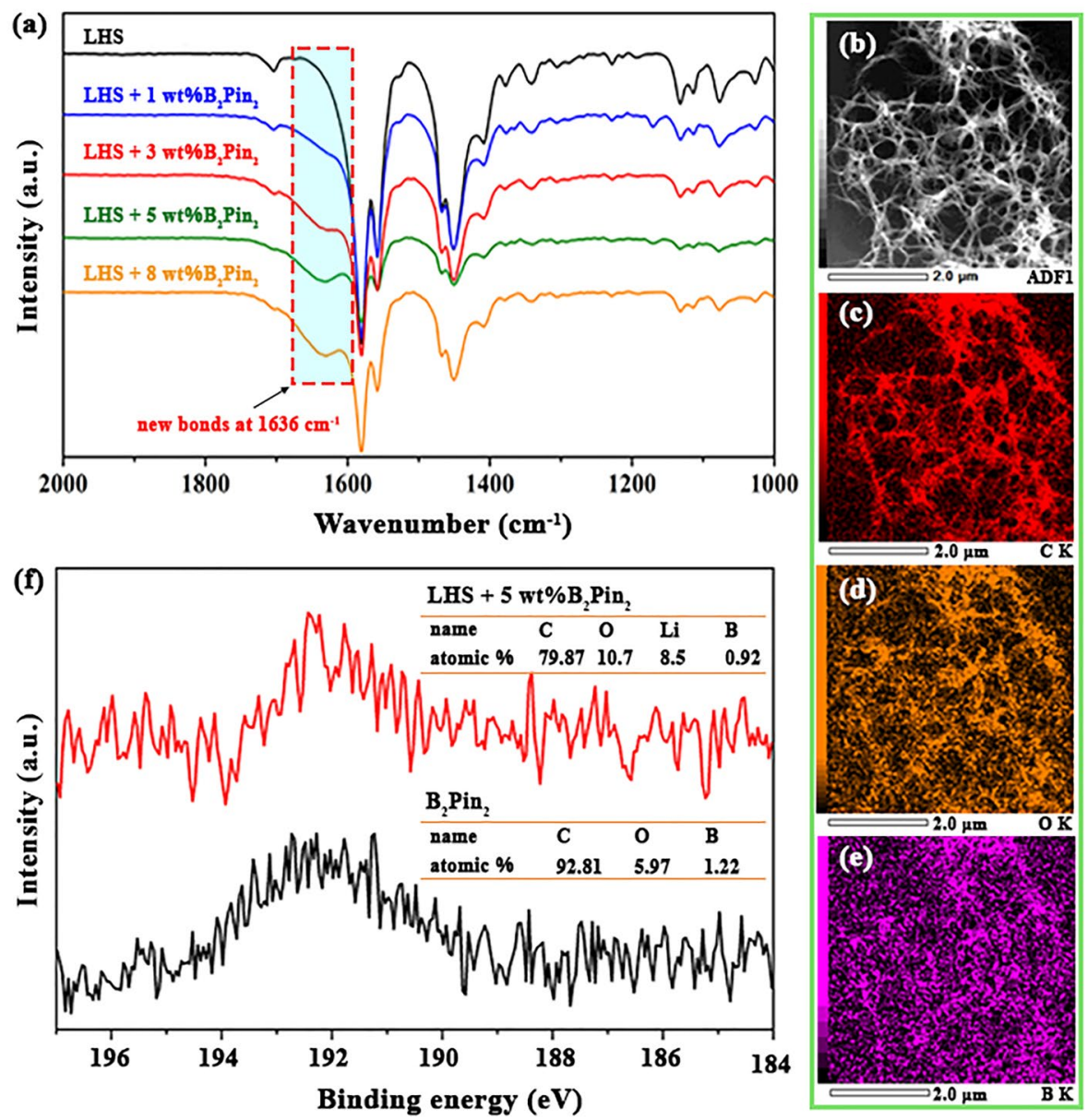

display that $\mathrm{B}$ phase mapping distributes over the area of $\mathrm{C}$ and $\mathrm{O}$ phase mapping, indicating boron containing layer on the surface of soap fiber structure. Additional evidence for the presence of $\mathrm{B}_{2} \mathrm{Pin}_{2}$ in the soap fiber structure comes from the B $1 s$ XPS spectrum for LHS $+5 \mathrm{wt} \% \mathrm{~B}_{2} \mathrm{Pin}_{2}$ (Fig. 1f). As expected, it can be observed that an obvious B $1 s$ peak located at about $192.3 \mathrm{eV}$, which is similar to that of pure $\mathrm{B}_{2} \mathrm{Pin}_{2}$. Quantitative analysis of LHS and LHS $+5 \mathrm{wt} \%$ $\mathrm{B}_{2} \mathrm{Pin}_{2}$ is reported (inset Tables of Fig. 1f) and shows the boron level of 0.92 atomic\% in LHS $+5 \mathrm{wt} \% \mathrm{~B}_{2} \mathrm{Pin}_{2}$, confirming the interaction of $\mathrm{B}_{2} \mathrm{Pin}_{2}$ with LHS to form the Lewis acid-base complex in the lubricating grease.

\subsection{Rheological Properties of Lithium Grease with Diboron}

Shear can result in mechanical breakdown of the thickeners [20]. In order to study the reinforcing effect of $\mathrm{B}_{2} \mathrm{Pin}_{2}$ on the fibrous structure of lithium grease, the rheological properties of fresh grease with varying $\mathrm{B}_{2} \mathrm{Pin}_{2}$ content were evaluated by shearing the greases in a rheometer at low and moderate temperature. In oscillatory shear measurements, shear modulus and shear stress versus strain are reported in Fig. 2 for the base grease with $0,1,3,5$, and $8 \mathrm{wt} \% \mathrm{~B}_{2} \mathrm{Pin}_{2}$ at $0{ }^{\circ} \mathrm{C}$, $30{ }^{\circ} \mathrm{C}$ and $60{ }^{\circ} \mathrm{C}$. When the modulus at strains outside the linear viscoelasticity (LVE) regime, all these greases exhibit transitions from $G^{\prime}$-dominant to $G^{\prime \prime}$-dominant behavior, corresponding to the structure transformation from the solidlike to liquid-like, and the transformation point indicates the decomposition point of grease crosslink structure. It is evident that at all shear strains, both storage $\left(G^{\prime}\right)$ and loss $\left(G^{\prime \prime}\right)$ for the grease with the addition of $\mathrm{B}_{2} \mathrm{Pin}_{2}$ are markedly higher than for the base grease at different temperatures, particularly for the grease with $5 \mathrm{wt} \% \mathrm{~B}_{2} \mathrm{Pin}_{2}$. Meanwhile, the corresponding shear stress deduced from these measurements is also greater than the base grease. These results mean that the lithium lubricating grease with the addition of $\mathrm{B}_{2} \mathrm{Pin}_{2}$ is both much stronger and more viscous than the base grease [21], which might be attributed to the formation of Lewis acid-base complex of LHS with $\mathrm{B}_{2} \mathrm{Pin}_{2}$ and the enhancement of the structure strength of lithium grease. In addition, it is seen that $5 \mathrm{wt} \% \mathrm{~B}_{2} \mathrm{Pin}_{2}$ is the optimum concentration to provide significant improvement for grease structure strength. In the shear experiment, evolution of viscosity with time at different shear rate and temperature for the base grease and the grease with $5 \mathrm{wt} \% \mathrm{~B}_{2} \mathrm{Pin}_{2}$ is shown 

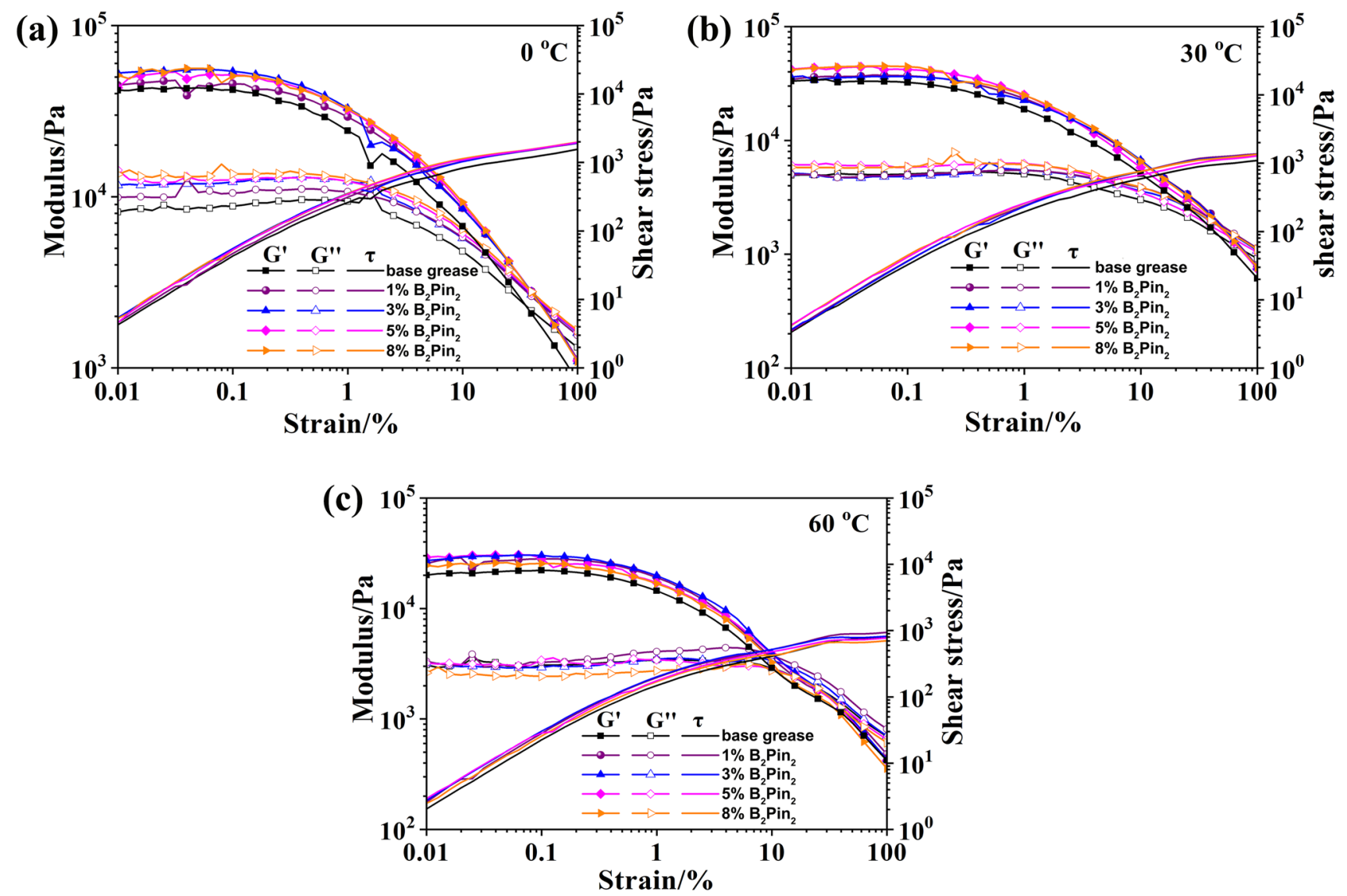

Fig. 2 Storage modulus $\left(G^{\prime}\right)$, loss modulus $\left(G^{\prime \prime}\right)$, and shear stress $(\tau)$ as a function of shear strain for lithium grease with various concentration of $\mathrm{B}_{2} \mathrm{Pin}_{2}$ at the temperature of $\mathbf{a} 0, \mathbf{b} 30$, and $\mathbf{c} 60^{\circ} \mathrm{C}$

in Fig. 3. At low value of shear rate $\left(0.01 \mathrm{~s}^{-1}\right)$, the viscosity of the grease with $5 \mathrm{wt} \% \mathrm{~B}_{2} \mathrm{Pin}_{2}$ is substantially higher than the viscosity of the base grease (Fig. 3a), especially for the viscosity at low temperature $\left(0{ }^{\circ} \mathrm{C}\right)$, which manifests a value around two orders of magnitude greater than that of the base grease, further demonstrating that soap fiber structure strength is significantly reinforced by the addition of $\mathrm{B}_{2} \mathrm{Pin}_{2}$. However, at high shear rate $\left(100 \mathrm{~s}^{-1}\right)$, the grease with $5 \mathrm{wt} \%$ $\mathrm{B}_{2} \mathrm{Pin}_{2}$ shows a slightly increase in viscosity compared to the base grease under low and moderate temperature. This can be explained by the fact that the grease thickener will not enter the contact surface but will be pushed to the sides at higher shear rate [22], leading to the formation of lubricating film primarily governed by the base oil [9].

\subsection{Tribological Properties of Lithium Grease with Diboron}

The lubrication performance of the lithium grease additized with $\mathrm{B}_{2} \mathrm{Pin}_{2}$ were investigated by SRV under variable temperatures, frequencies and loads. Firstly, the friction coefficient of the base grease with $0,1,3,5$, and $8 \mathrm{wt} \% \mathrm{~B}_{2} \mathrm{Pin}_{2}$ measured at a constant load of $200 \mathrm{~N}$, a fixed frequency of $25 \mathrm{~Hz}$, and different temperature of 30 and $60{ }^{\circ} \mathrm{C}$ are displayed in Fig. 4. It is seen that the base grease has a relatively long running-in time (around 0-300 s) with very high friction coefficient $(>0.2)$ at $30^{\circ} \mathrm{C}$ (Fig. 4a). However, the addition of $\mathrm{B}_{2} \mathrm{Pin}_{2}$ can dramatically reduce the running-in period and shows lightly reduce friction coefficient. When the temperature is increased to $60{ }^{\circ} \mathrm{C}$ (Fig. 4c), the friction coefficients are noticeably lower than that obtained for the base grease. In particular, $5 \mathrm{wt} \% \mathrm{~B}_{2} \mathrm{Pin}_{2}$ is the optimum concentration to reduce the friction coefficient (up to 19\%) compared to that of $1 \mathrm{wt} \%$ (8\%), $3 \mathrm{wt} \%$ (14\%), and $8 \mathrm{wt} \%(16 \%)$ $\mathrm{B}_{2} \mathrm{Pin}_{2}$. Moreover, $\mathrm{B}_{2} \mathrm{Pin}_{2}$ additivated grease also exhibits exceptional AW performance, as shown in Fig. $4 \mathrm{~b}$ and d. The addition of $5 \mathrm{wt} \% \mathrm{~B}_{2} \mathrm{Pin}_{2}$ reduced the wear volume of the base grease by 12 times and 3 times at $30^{\circ} \mathrm{C}$ and $60^{\circ} \mathrm{C}$, respectively, providing stronger protection against wear than other concentrations of $\mathrm{B}_{2} \mathrm{Pin}_{2}$. Figure 5 also show the $3 \mathrm{D}$ morphology of the wear scars in Fig. $4 \mathrm{~b}$ and d. Compared with the base grease, the addition of $\mathrm{B}_{2} \mathrm{Pin}_{2}$ generated shallower and narrower wear scars, while the wear scars generated by base grease are deeper and wider, so it is significant 

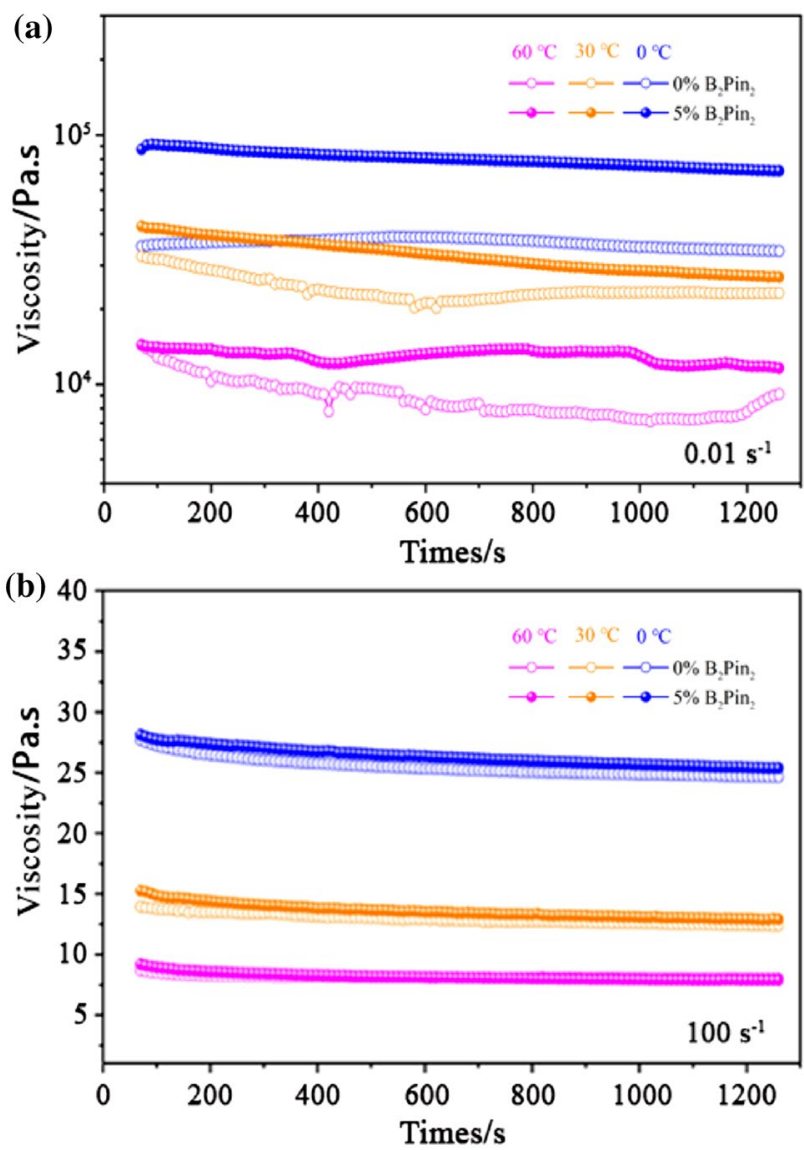

Fig. 3 The evolution of shear viscosity for lithium grease and the grease with $5 \mathrm{wt} \% \mathrm{~B}_{2} \mathrm{Pin}_{2}$ at shear rate of $\mathbf{a} 0.01 \mathrm{~s}^{-1}$ and $\mathbf{b} 100 \mathrm{~s}^{-1}$ at different temperatures

that the use of $\mathrm{B}_{2} \mathrm{Pin}_{2}$ prevents the formation of wear scars larger and deeper. The excellent friction and wear reduction properties could probably be ascribed to the boundary lubrication film formed by $\mathrm{B}_{2} \mathrm{Pin}_{2}$ adsorbed on the sliding surface and/or tribochemical reaction between borate esters and steel surfaces $[12,14]$.

The lubricating performance of $5 \mathrm{wt} \% \mathrm{~B}_{2} \mathrm{Pin}_{2}$ added in the grease was further evaluated by changing the reciprocating frequencies and applied loads. As shown in Fig. 6a and $\mathrm{b}$, the addition of $5 \mathrm{wt} \% \mathrm{~B}_{2} \mathrm{Pin}_{2}$ could contribute efficiently to the friction reduction of base grease during frequency ramp test from 10 up to $70 \mathrm{~Hz}$ stepped by $15 \mathrm{~Hz}$ at different temperatures, particularly as the frequency below $40 \mathrm{~Hz}$. In addition, Fig. $6 \mathrm{c}$ and d display the load-carrying capacity of $5 \mathrm{wt} \% \mathrm{~B}_{2} \mathrm{Pin}_{2}$ additivated grease increased remarkably from 100 and $150 \mathrm{~N}$ to $500 \mathrm{~N}$ with increase in applied load from 50 to $500 \mathrm{~N}$ at $30^{\circ} \mathrm{C}$ and $60{ }^{\circ} \mathrm{C}$, respectively. The improvement of anti-shear and load-carrying capacities of lithium grease may be attributed to the reinforcement of the grease structure strength and the formation of boundary lubrication film by the addition of $\mathrm{B}_{2} \mathrm{Pin}_{2}$.

\subsection{Surface Analysis of Wear Scars Lubricated by Lithium Grease with Diboron}

To investigate the friction reduction and AW mechanism of $\mathrm{B}_{2} \mathrm{Pin}_{2}$ in lithium grease, high-resolution (HR) XPS spectra of $\mathrm{B}, \mathrm{O}$ and $\mathrm{Fe}$ on the worn surface of the steel discs were obtained. As shown in Fig. 7a, the binding energies of $\mathrm{B} 1 s$ on the worn scars lubricate by the base grease with the addition $\mathrm{B}_{2} \mathrm{Pin}_{2}$ at $30{ }^{\circ} \mathrm{C}$ and $60{ }^{\circ} \mathrm{C}$ are similar to each other, and the peaks centered at $193.5 \mathrm{eV}$ and $192.0 \mathrm{eV}$ might be ascribed to $\mathrm{B}-\mathrm{B}$ and $\mathrm{B}-\mathrm{O}$ binds related to $\mathrm{B}_{2} \mathrm{Pin}_{2}$ residue and $\mathrm{B}_{2} \mathrm{O}_{3}[15,23]$. The $\mathrm{O} 1$ s XPS spectra for the wear scars lubricated with the base grease at $30{ }^{\circ} \mathrm{C}$ and $60{ }^{\circ} \mathrm{C}$ are also very similar, and one of them can be deconvoluted into five peaks, which appear at $529.1 \mathrm{eV}, 529.8 \mathrm{eV}, 530.8 \mathrm{eV}, 531.7 \mathrm{eV}$ and $532.7 \mathrm{eV}$, are identified to $\mathrm{Fe}_{3} \mathrm{O}_{4}, \mathrm{Fe}_{2} \mathrm{O}_{3}$, and LHS (Fig. 7b) [23]. After lubricating with the grease additized $\mathrm{B}_{2} \mathrm{Pin}_{2}$ at $30{ }^{\circ} \mathrm{C}$ and $60{ }^{\circ} \mathrm{C}$ (Fig. $7 \mathrm{~b}$ ), the $\mathrm{O} 1 \mathrm{~s}$ spectra including three and five peaks, which might be assigned to LHS (530.8 eV, $531.7 \mathrm{eV})$ and $\mathrm{B}_{2} \mathrm{Pin}_{2}(532.6 \mathrm{eV})$ residues, and $\mathrm{Fe}_{2} \mathrm{O}_{3}$ (529.8 eV), $\mathrm{Fe}_{3} \mathrm{O}_{4}(530.1 \mathrm{eV})$, LHS (530.8 eV, $\left.531.7 \mathrm{eV}\right)$ and $\mathrm{B}_{2} \mathrm{Pin}_{2}(532.6 \mathrm{eV})$ residues, respectively [23, 24]. In addition, the XPS spectra of Fe $2 p$ display four peaks and five peaks when the lubricating grease with $\mathrm{B}_{2} \mathrm{Pin}_{2}$ were evaluated at $30{ }^{\circ} \mathrm{C}$ and $60{ }^{\circ} \mathrm{C}$ (Fig. 7c), these peaks were corresponded to $\mathrm{FeO}$ (709), $\mathrm{Fe}_{3} \mathrm{O}_{4}(709.8 \mathrm{eV}), \mathrm{Fe}_{2} \mathrm{O}_{3}$ (710.8 eV and $724 \mathrm{eV}$ ), and $\mathrm{Fe}(\mathrm{OH}) \mathrm{O}(712 \mathrm{eV})$ [23, 25], respectively. These results demonstrate that the addition of $\mathrm{B}_{2} \mathrm{Pin}_{2}$ in the lithium grease could adsorb on the contact surfaces and generate tribochemical products to form boundary lubrication film at $30{ }^{\circ} \mathrm{C}$ and $60{ }^{\circ} \mathrm{C}$. The film contains $\mathrm{FeO}, \mathrm{Fe}_{3} \mathrm{O}_{4}, \mathrm{Fe}_{2} \mathrm{O}_{3}, \mathrm{Fe}(\mathrm{OH}) \mathrm{O}, \mathrm{B}_{2} \mathrm{O}_{3}$, and $\mathrm{B}_{2} \mathrm{Pin}_{2}$ residue, which is beneficial to improving the tribological properties of the lithium grease during friction and wear process. 

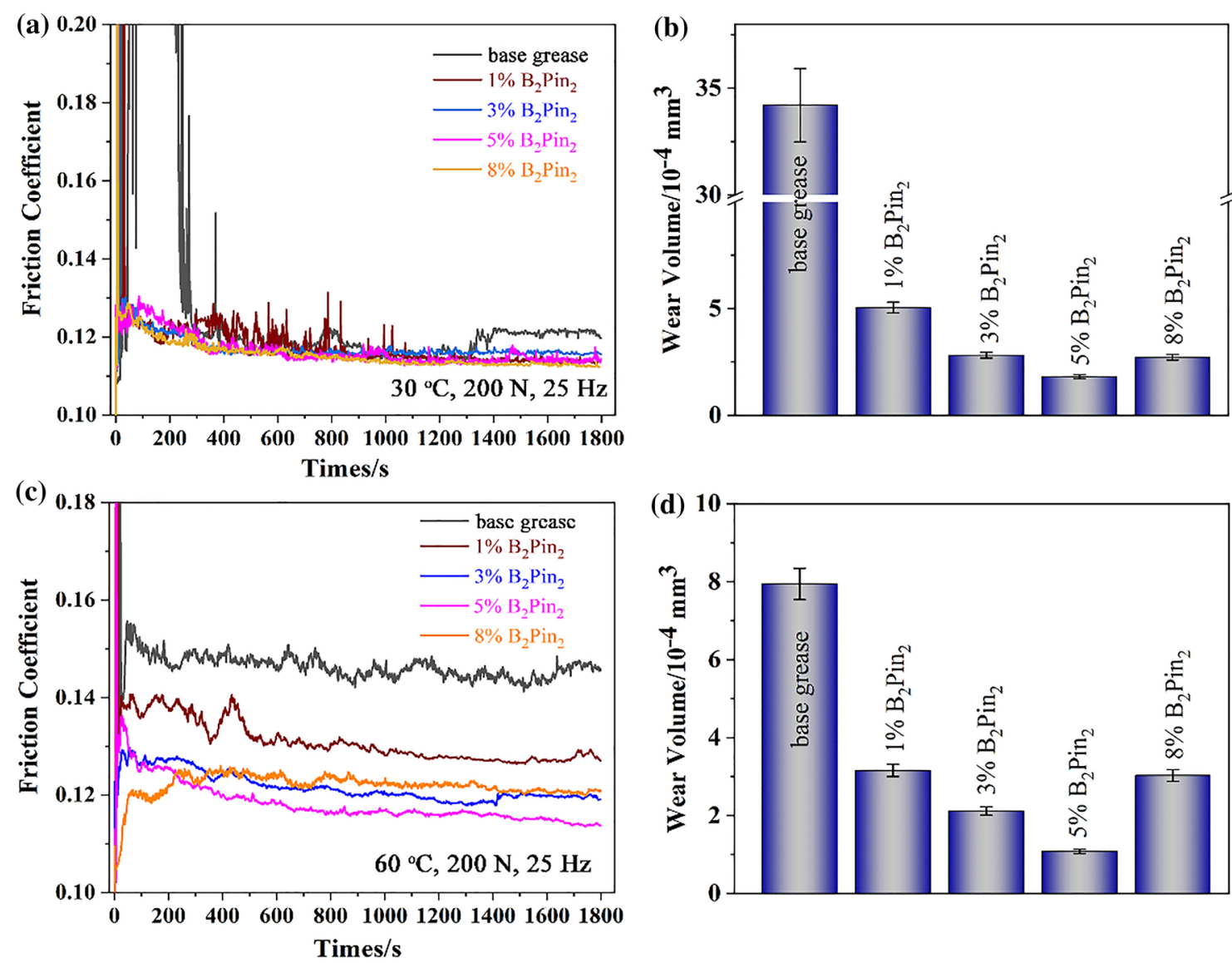

Fig. 4 a, $\mathbf{c}$ Friction coefficient and $\mathbf{b}$, $\mathbf{d}$ wear volume of steel discs lubricated by lithium grease and the grease with different concentration of $\mathrm{B}_{2} \mathrm{Pin}_{2}$ at $\mathbf{a}, \mathbf{b} 30$ and $\mathbf{c}, \mathbf{d} 60^{\circ} \mathrm{C}$ (SRV load, $200 \mathrm{~N}$; stroke, $1 \mathrm{~mm}$; frequency, $25 \mathrm{~Hz}$ )

\section{Conclusions}

To sum up, the interaction of bis(pinacolato) diboron $\left(\mathrm{B}_{2} \mathrm{Pin}_{2}\right)$ with lithium 12-hydroxystearate (LHS) in lithium grease was characterized, and the rheological and tribological performance of the grease additized with $\mathrm{B}_{2} \mathrm{Pin}_{2}$ was investigated at low and moderate temperatures. The following conclusions can be drawn from the present study:

(1) The formation of Lewis acid-base complex of LHS with $\mathrm{B}_{2} \mathrm{Pin}_{2}$ was confirmed. In this reaction, each boron atom of $\mathrm{B}_{2} \mathrm{Pin}_{2}$ tends to donate an electron pair to one carbonyl oxygen atom of $\mathrm{RCO}_{2}^{-}$in LHS, resulting in the combination of boron atom (Lewis acid) with the carbonyl oxygen atom (Lewis base).
(2) Rheological analysis demonstrates that the combination of $\mathrm{B}_{2} \mathrm{Pin}_{2}$ with LHS obviously reinforced the soap fiber structure strength of lithium grease at low temperature and low shear speed, and $5 \mathrm{wt} \% \mathrm{~B}_{2} \mathrm{Pin}_{2}$ is the optimum concentration to provide the significant improvement.

(3) Tribological experiments clearly show that the addition of $5 \mathrm{wt} \% \mathrm{~B}_{2} \mathrm{Pin}_{2}$ reduced the friction coefficient up to $19 \%$ and the wear volume by around 12 times compared with the base grease and enhanced the anti-shear and load-carrying capacities of lithium grease at $30^{\circ} \mathrm{C}$ and $60{ }^{\circ} \mathrm{C}$, respectively.

(4) The excellent tribological behaviors of $\mathrm{B}_{2} \mathrm{Pin}_{2}$ in the grease are ascribed to the formation of boundary lubrication film generated by $\mathrm{B}_{2} \mathrm{Pin}_{2}$ adsorbed on the rubbing surface and tribochemical reaction between borate esters and steel. 

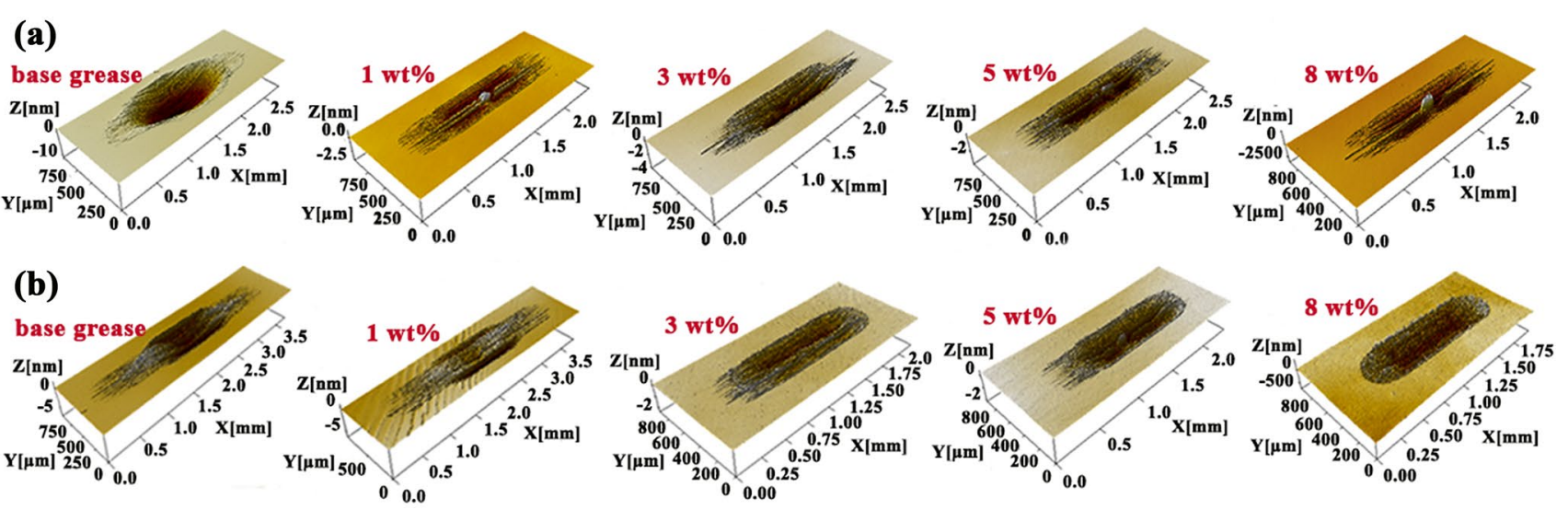

Fig. 5 The 3D optical microscopic images of wear track lubricated by lithium grease and the grease with different concentration of $\mathrm{B}_{2}$ Pin ${ }_{2}$ at $\mathbf{a}$ 30 and $\mathbf{b} 60^{\circ} \mathrm{C}$ (SRV load, $200 \mathrm{~N}$; stroke, $1 \mathrm{~mm}$; frequency, $25 \mathrm{~Hz}$ )

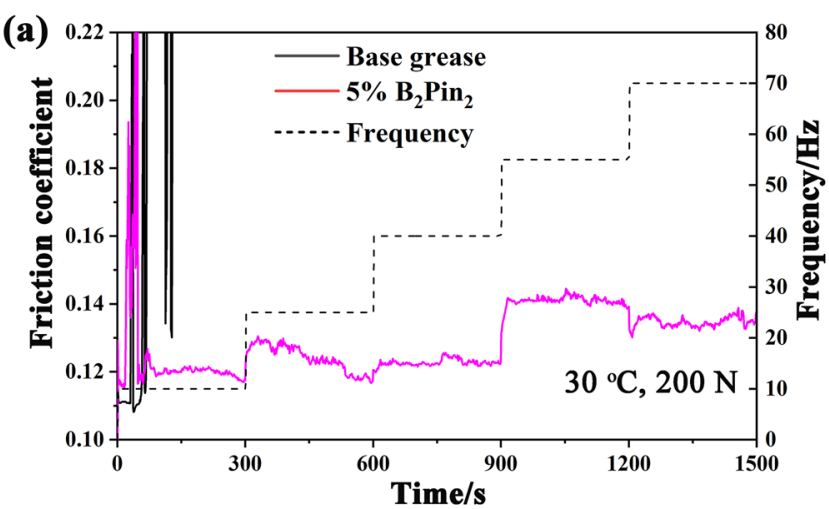

(c)

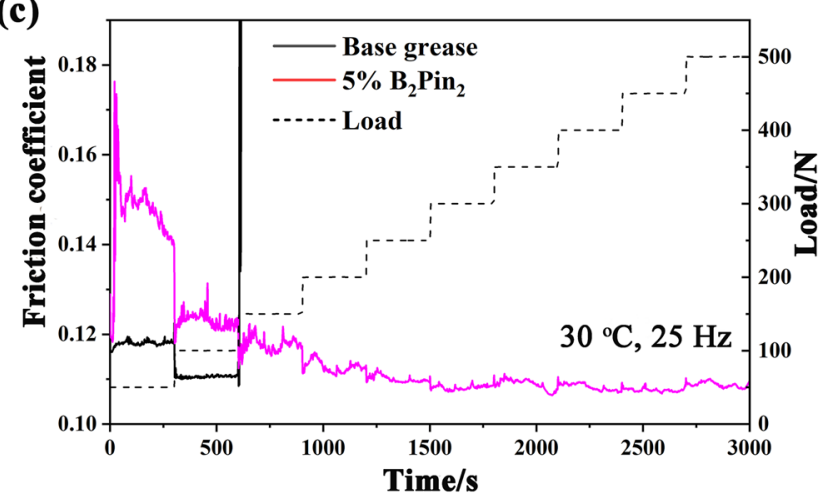

Fig. 6 The variation of friction coefficient as a function of time during a a, b frequence load ramp test from 10 to $70 \mathrm{~Hz}$ and a $\mathbf{c}, \mathbf{d}$ load ramp test from 50 to $500 \mathrm{~N}$ at $\mathbf{a}, \mathbf{c} 30$ and $\mathbf{b}, \mathbf{d} 60^{\circ} \mathrm{C}$ (SRV conditions
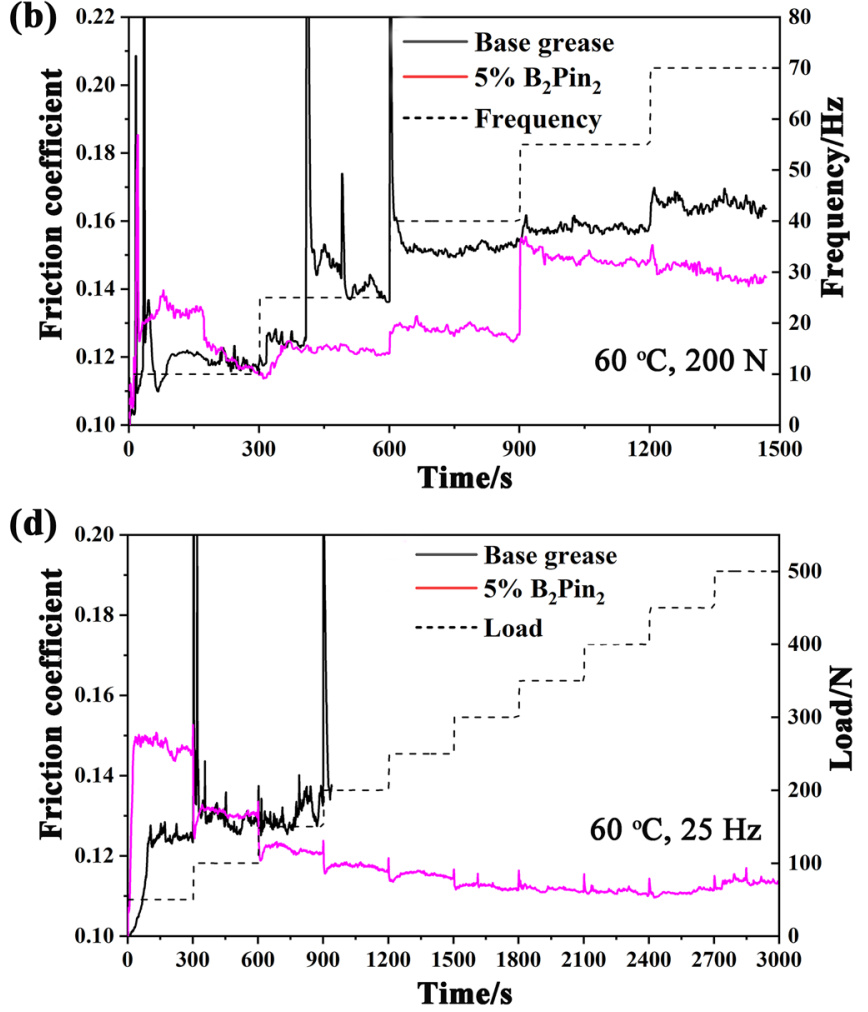

for frequence test: frequence, $10-70 \mathrm{~Hz}$; load, $200 \mathrm{~N}$; stroke, $1 \mathrm{~mm}$, and for load ramp test: load, 50-500 N; stroke, $1 \mathrm{~mm}$; frequency, $25 \mathrm{~Hz}$ ) 

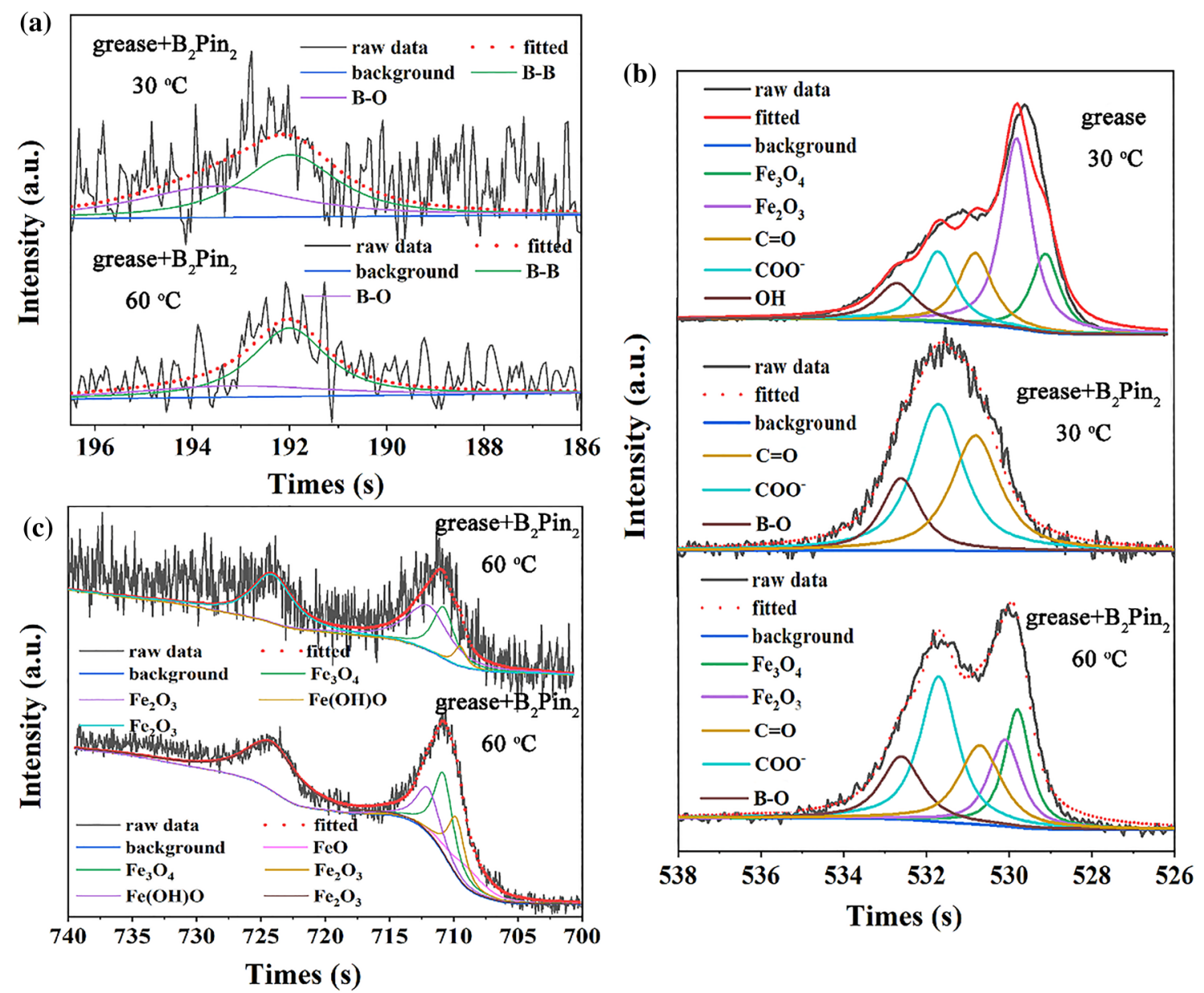

Fig. 7 High-resolution XPS spectra of a B $1 s, \mathbf{b}$ O $1 s$, and $\mathbf{c}$ Fe $2 p$ for the steel discs lubricated by lithium grease and the grease with 5 wt $\%$ $\mathrm{B}_{2} \mathrm{Pin}_{2}$ at 30 and $60{ }^{\circ} \mathrm{C}$ (SRV load, $200 \mathrm{~N}$; stroke, $1 \mathrm{~mm}$; frequency, $25 \mathrm{~Hz}$ )

Acknowledgements The authors are thankful for financial support of this work by National Key Research and Development Program of China (Grant No. 2018YFB2000601) and National Natural Science Foundation of China (Grant No. NSFC 51875553)

Author Contributions Not applicable.

Funding The research was funded by National Key Research and Development Program of China (Grant No. 2018YFB2000601) and National Natural Science Foundation of China (Grant No. NSFC 51875553).

Data Availability Not applicable.

Code Availability Not applicable.

\section{Declarations}

Conflict of interest The authors declare no competing financial interest.
Ethical Approval Not applicable.

Consent to Participate Not applicable.

Consent for Publication Not applicable.

Open Access This article is licensed under a Creative Commons Attribution 4.0 International License, which permits use, sharing, adaptation, distribution and reproduction in any medium or format, as long as you give appropriate credit to the original author(s) and the source, provide a link to the Creative Commons licence, and indicate if changes were made. The images or other third party material in this article are included in the article's Creative Commons licence, unless indicated otherwise in a credit line to the material. If material is not included in the article's Creative Commons licence and your intended use is not permitted by statutory regulation or exceeds the permitted use, you will need to obtain permission directly from the copyright holder. To view a copy of this licence, visit http://creativecommons. org/licenses/by/4.0/. 


\section{References}

1. Wang, D.F., Yang, J.L., Wei, P.C., Pu, W.: A mixed EHL model of grease lubrication considering surface roughness and the study of friction behavior. Tribol. Int. 154, 106710 (2021)

2. Cen, H., Lugt, P.M.: Film thickness in a grease lubricated ball bearing. Tribol. Int. 134, 26-35 (2019)

3. Varebberg, M., Kligerman, Y., Halperin, G., Nakad, S., Kasem, K.: Assessing workability of greased bearings after long-term storage. Friction 7, 489-496 (2019)

4. Laurentis, N.D., Cann, P., Lugt, P.M., Kadiri, A.: The influence of base oil properties on the friction behaviour of lithium greases in rolling/sliding concentrated contacts. Tribol. Lett. 65, 128 (2017)

5. Lugt, P.M.: A review on grease lubrication in rolling bearings. Tribol. Trans. 52, 470-480 (2009)

6. Mortier, R.M., Fox, M.F., Orszulik, S.T.: Chemistry and Technology of Lubricants. Springer, New York (2010)

7. Cen, H., Lugt, P.M., Morales-Espejel, G.: Film thickness of mechanically worked lubricating grease at very low speeds. Tribol. Trans. 57, 1066-1071 (2014)

8. Ito, H., Tomaru, M., Suzuki, T.: Physical and chemical aspects of grease deterioration in sealed ball bearings. Lubr. Eng. 44, 872-879 (1988)

9. Cen, H., Lugt, P.M., Morales-Espejel, G.: On the film thickness of grease-lubricated contacts at low speeds. Tribol. Trans. 57, 668-678 (2014)

10. Martín-Alfonso, J.E., Martín-Alfonso, M.J., Valencia, C., Cuberes, M.T.: Rheological and tribological approaches as a tool for the development of sustainable lubricating greases based on nano-montmorillonite and castor oil. Friction 9, 415$428(2021)$

11. Martín-Alfonso, J.E., Valencia, C.: Tribological, rheological, and microstructural characterization of oleogels based on EVA copolymer and vegetables oils for lubricant applications. Tribol. Int. 90, 426-434 (2015)

12. Li, W., Wu, Y., Wang, X., Liu, W.: Tribological study of boroncontaining soybean lecithin as environmentally friendly lubricant additive in synthetic base fluids. Tribol. Lett. 47, 381-388 (2012)

13. Yan, J., Zeng, X., van der Heide, E., Ren, T.: The tribological performance and tribochemical analysis of novel borate esters as lubricant additives in rapeseed oil. Tribol. Int. 71, 149-157 (2014)

14. Philippon, D., De Barros-Bouchet, M.-I., Lerasle, O., Le Mogne, T., Martin, J.-M.: Experimental simulation of tribochemical reactions between borates esters and steel surface. Tribol. Lett. 41, 73-82 (2011)
15. Xu, N., Li, W.M., Zhang, M., Wang, X.B.: Reinforcing effect of Lewis acid-base interaction on the high-temperature colloidal stability and tribological performance of lubricating grease. J. Ind. Eng. Chem. 46, 157-164 (2017)

16. Cao, Y., Zhou, P., Tu, Y.G., Liu, Z., Dong, B.W., Azad, A., Ma, D.G., Wang, D., Zhang, X., Yang, Y., Jiang, S.D., Zhu, R., Guo, S.J., Mo, F.Y., Ma, W.H.: Modification of $\mathrm{TiO}_{2}$ nanoparticles with organodiboron molecules inducing stable surface $\mathrm{Ti}^{3+}$ complex. iScience 20, 195-204 (2019)

17. Cao, Y., Tu, Y.G., Zhou, P., Zhang, J.N., Deng, Y.C., Kong, B., Zhang, X., Guo, S.J., Zhu, R., Ma, D., Yang, Y., Mo, F.Y.: Zn ${ }^{+}$ $\mathrm{O}^{-}$dual-spin surface state formation by modification of $\mathrm{ZnO}$ nanoparticles with diboron compounds. Langmuir 35, 14173-14179 (2019)

18. Tu, Y.G., Yang, X.Y., Su, R., Luo, D.Y., Cao, Y., Zhao, L.C., Liu, T.H., Yang, W.Q., Zhang, Y.F., Xu, Z.J., Liu, Q.Z., Wu, J.H., Gong, Q.H., Mo, F.Y., Zhu, R.: Diboron-assisted interfacial defect control strategy for highly efficient planar perovskite solar cells. Adv. Mater. 30, 1805085 (2018)

19. Xu, N., Li, W.M., Zhang, M., Zhao, G.Q., Wang, X.B.: New insight to the tribology-structure interrelationship of lubricating grease by a rheological method. RSC Adv. 5, 54202 (2015)

20. Moses, G.B., Puddington, I.E.: The rheological properties of some soap-oil systems. Can. J. Chem. 29, 996-1009 (1951)

21. Kim, D., Archer, L.A.: Nanoscale organic-inorganic hybrid lubricants. Langmuir 27, 3083-3094 (2011)

22. Cann, P.M.: Understanding grease lubrication. Tribol Series 31, 573-581 (1996)

23. NIST X-ray Photoelectron Spectroscopy Database, version 4.1; National Institute of Standards and Technology, Gaithersburg, MD, 2012, http://srdata.nist.gov/xps/ accessed March 2013.

24. Wu, X.H., Gong, K.L., Zhao, G.Q., Lou, W.J., Wang, X.B., Liu, W.M.: Surface modification of $\mathrm{MoS}_{2}$ nanosheets as effective lubricant additives for reducing friction and wear in poly- $\alpha$-olefin. Ind. Eng. Chem. Res. 57, 8105-8114 (2018)

25. Cai, M.R., Liang, Y.M., Zhou, F., Liu, W.M.: Tribological properties of novel imidazolium ionic liquids bearing benzotriazole group as the antiwear/anticorrosion additive in poly(ethylene glycol) and polyurea grease for steel/steel contacts. ACS Appl. Mater. Interfaces 3, 4580-4592 (2011)

Publisher's Note Springer Nature remains neutral with regard to jurisdictional claims in published maps and institutional affiliations. 